DOI 10.37882/2500-3682.2021.04.01

\title{
ДВУХФАКТОРНАЯ МОДЕЛЬ СЧАСТЬЯ, ВЗАИМОЗАВИСИМОСТЬ И ДИНАМИКА ФАКТОРОВ
}

\section{TWO-FACTOR MODEL OF HAPPINESS, INTERDEPENDENCE AND DYNAMICS OF FACTORS}

\section{Andreev}

Summary: This article is devoted to the clarification of the two-factor model of happiness (hedonia-eudaimonia), formulated in antiquity. A detailed description of two factors of consideration of the state of happiness proposed by Daniel Kahneman is given - experienced wellbeing and remembering of well-being; adequate, in the author's opinion, translations of these terms into Russian are offered. The article also analyzes in detail the structure of the factors of happiness, their nature and the specificity of the experience, analyzes the dynamics of changes in the factors of happiness over time and their interdependence. The introduced concepts of situational and integral tone, reflecting the factors of happiness, initially assume a certain dimension and modality of the corresponding characteristics of happiness. which makes it possible to characterize much more accurately both the current state of a person (hedonistic factor) and the general level of a person's happiness-unhappiness (eudemonic factor). A situational tone (high or low) characterizes the momentary, predominantly emotional perception of the feeling of happiness. Integral tone (high or low) characterizes the general feeling of a person - his success, characteristics of his environment, accumulated benefits, health status, formed skills and personal characteristics, confidence in the future and other objective characteristics of life. The modalities of the situational and integral tone (high-low) make it possible to accurately describe the current state of a person in the coordinates happiness - unhappiness. It also analyzes the degree of dependence and at the same time the relative independence of changes in the two factors of happiness and the possibility of influencing them, both in the process of personal work on oneself and in the future, helping relationships - psycho-counseling or coaching.

Keywords: happiness, two-factor model of happiness, hedonia, eudaimonia, experienced well-being, remembering of well-being, situational tone, integral tone, emotional background, low-tone and high-tone states, positive psychology.
$\mathrm{H}$ еоднородность интерпретации понятия счастья осознавалась с момента зарождения европейской гуманитарной мысли. Так, еще философами досократиками оно, с одной стороны, «ассоциировалась с такими понятиями как «наслаждение», «длительное состояние удовольствия», «веселое настроение безмятежности», «ощущение полноты бытия и радости», «блаженство»[3, с.12], то есть с позитивными субъективными переживаниями. Но с другой, уже Демокрит (5 в до н.э.)
Андреев Владимир Сергеевич

Аспирант, Институт психологии творчества 9979549@gmail.com

Аннотация: Данная статья посвящена уточнению двухфакторной модели счастья (гедония-эвдемония), сформулированной еще в античности. Дается детальная характеристика двух факторов рассмотрения состояния счастья, предложенных Дениэлем Канеманом - experienced well-being и remembering of well-being, предлагаются адекватные, по мнению автора, переводы этих терминов на русский язык. Так же в статье детально анализируется структура факторов счастья, их природа и специфика переживания, анализируется динамика изменения факторов счастья во времени и их взаимозависимость. Введенные понятия ситуативного и интегрального тона, отображающих факторы счастья, изначально предполагают определенную мерность и модальность соответствующих характеристик счастья. что позволяет гораздо более точно характеризовать как текущее состояние человека (гедонистический фактор), так и общий уровень счастья-несчастья человека (эвдемонический фактор). Ситуативный тон (высокий или низкий) характеризует сиюминутное, преимущественно эмоциональное восприятие ощущения счастья. Интегральный тон (высокий или низкий) характеризует общее ощущение человека - его успешность, характеристики его окружения, накопленные блага, состояние здоровья, сформированные навыки и личностные характеристики, уверенность в будущем и другие объективные характеристики жизни. Модальности ситуативного и интегрального тона (высокий-низкий) позволяют достаточно точно описывать текущее состояния человека в координатах счастье - несчастье. Так же анализируется степень зависимости и одновременно относительной самостоятельности изменения двух факторов счастья и возможности воздействия на них, как в процессе персональной работы над собой так и в перспективе помогающих отношений - психо-консультирования или коучинга.

Ключевые слова: счастье, двухфакторная модель счастья, гедония, эвдемония, experienced well-being, remembering of well-being, ситуативный тон, интегральный тон, эмоциональный фон, низко-тональные и высоко-тональные состояния, позитивная психология. 
результат определенного развития и обладание определенными характеристиками личности.

Эту идею двухфакторности счастья в античной мысли окончательно закрепил Аристотель [2], сформулировав два истолкования понимания счастья как гедонистическое (ориентированное на получение максимального количества удовольствий в жизни) и эвдемоническое («которое связано с реализацией человеком собственных уникальных достоинств и добродетелей («дэймона») в соответствующей ему деятельности» $[4$, с.56])

Идею Счастья как реализации определенного набора личностных качеств в дальнейшем активно развивали древнеримские философы, принадлежавшие к кругу поздних стоиков. Так, например, по мнению Марка Аврелия умение быть счастливым заключается в умении стойко переносить невзгоды «во всем, что наводит на тебя печаль, надо опираться на такое положение: не это - несчастье, а мужественно переносить это - счастье»[1, c. 15].

В современной научной психологии уже в конце 20 века к идее двух способов рассмотрения понятия счастья возвращается Даниэл Канеман. В своей работе посвященной исследованию феномена Счастья [12] он фиксирует, что при оценке уровня счастья оно интерпретируется двумя совершенно различными способами.

Первый способ (получивший название, experienced well-being) - связан с оценкой сиюминутного состояния, как физиологических ощущений (удобно - неудобно, тепло - холодно, болит - не болит), так и испытываемых эмоций (позитивные - негативные). Именно о подобной интерпретации понятия счастье говорится в теории «объективного счастья» Каннемана [13, с. 254], работах Дэвиса [9], Самнера [16].

Второй способ (remembering of well-being) базируется на оценке объективных фактов жизни - уровня благосостояния, семейного положения, удовлетворенности от работы, наличия круга друзей, социального статуса, наличия практических навыков и умений и множества других вполне параметров, наличие которых приносит человеку общее удовлетворение. Данный способ рассмотрения счастья включает, как вполне объективируемые параметры, так и исключительно субъективные, связанные с личными интерпретациями тех или иных событий жизненной истории, а также индивидуальными характеристиками личности. Если первый способ интерпретации счастья является комплексом сиюминутных переживаний, то второй - это скорее история (нарратив), характеризующая жизнь во всей ее совокупности, хранящаяся в индивидуальном сознании субъекта.

Прежде чем продолжать детальное рассмотрение этих двух аспектов счастья необходимо дать им адекват- ные переводы на русский язык. К сожалению, устойчивых трансляций данных понятий в русскоязычной литературе не имеется. Прямой перевод как «испытываемое благополучие» и «воспоминание о благополучии» очевидно абсолютно не адекватны и не передают сущности феномена. Само слово благополучие в русском языке не ассоциируется напрямую со словом счастье, а подчас даже противопоставляются ему.

П.М. Пискарев в своей диссертационной работе «Метамодерн и интегративная методология гуманитарного знания» переводит данные термины как «счастье испытывающего Я» и «счастье помнящего Я» [5, с.248]. Данные переводы куда более адекватны, но также имеют определённые недостатки. С одной стороны они требуют предварительного рассмотрения концепция «помнящего и испытывающего Я», а с другой ни первый, ни второй аспект рассмотрения не дают собственно толкования счастья как комплексного феномена, а обозначают лишь один из аспектов его рассмотрения, не передающих феномена счастья во всей его полноте. Так, например, человек переживающий ощущение сильного удовольствия в определенный момент времени, которое можно было бы характеризовать как переживание «счастья» в контексте experienced well-being, может быть в целом абсолютно не удовлетворен своей жизненной ситуацией и испытывать огромные проблемы в жизни. И с этой точки зрения (remembering of well-being) его можно охарактеризовать как абсолютно несчастного. Примеров подобных ситуаций можно привести множество, например, человек, проживающий в нищете и испытывающий продолжительное состояние голода, получивший пищу будет испытывать сиюминутное ощущение «полного счастья», при этом оставаясь абсолютно несчастным.

С другой стороны, два обсуждаемых аспекта рассмотрения счастья изначально подразумевают вариативность. И переживание в настоящий момент, и накопленные блага, и благодетели могут носить как положительный, так и отрицательных характер. В то время как использование слова счастье в выражениях «счастье испытывающего Я» и «счастье помнящего Я» - скорее фиксирует некоторый эталон позитивного состояния.

Таким образом, перевод термина «well-been» словом «счастье» в рассматриваемом контексте не может считаться адекватным. Вообще английскому слову wellbeing достаточно трудно подобрать адекватный перевод, хорошо передающий контекст обсуждения.

Например, термин «удовлетворённость» в отличие от терминов счастье или благополучие изначально отражает вариативность переживания. Удовлетворённость может быть высокой и низкой, человек может быть более или менее удовлетворенным. Но в то же время в российском менталитете удовлетворенность и счастье отнюдь не воспринимаются как синонимы. Счастье как духов- 
ная и динамичная сущность подчас противопоставляется удовлетворенности как чему-то приземленному и инертному.

В последнее время в психологии для выражения уровня удовольствия/неудовольствия в текущий момент стал применяться термин «эмоциональный тон» [6, c. 6]. На наш взгляд именно это словосочетание является достаточно неплохим смысловым аналогом англоязычного термина experienced well-being, применяемого в контексте рассмотрения одного из факторов счастья. Однако степень удовольствия и неудовольствия, испытываемые в конкретный момент времени, характеризуется не только эмоциональным компонентом, но и другими составляющими, такими как наличие или отсутствие физической боли или тех или иных позитивных или негативных физиологических ощущений (тошнота, ощущение насыщения). Поэтому мы предлагаем в качестве перевода понятия experienced well-being использовать русскоязычный термин «ситуативный тон» (или уровень ситуативного тона). Слово тон применяется в различных контекстах именно для акцентирования на вариативности описываемой сущности и изначально подразумевает динамичность характеристики объекта (высокий - низкий музыкальный тон, дурной-возвышенный тон общения, яркий-бледный тон красок).

Соответственно ситуативный тон характеризует степень положительности-отрицательности сиюминутного переживания. Тон может быть как высоким - когда человеку хорошо в настоящий момент, так и низким, когда ему плохо. При этом ситуативный тон будет характеризовать не только эмоциональный тон, но и все составляющие степени сиюминутного удовольствия/неудовольствия.

Соответственно для перевода remembering of wellbeing предлагается использовать термин «интегральный тон» (или уровень интегрального тона). Слово интегральный в данном контексте является синонимом слова суммарный (итоговый) - счастье, как некоторый объективный итог прожитой жизни, приобретенных объективных достижений и качеств, и субъективных характеристик, а также перспектив и видения будущего.

Интегральный тон, также может быть положительным (высоким), в том случае, если человек доволен собой, своим жизненным положением и перед ним открываются богатые перспективы в будущем, или негативным (низким) в обратном случае.

Введенные понятия ситуативного и интегрального тона позволяют гораздо более точно характеризовать состояние человека, во-первых, вводя определенную мерность (можно говорить о высоком, среднем или низком ситуативном и интегральном тоне и даже различать более тонкие количественные различия), а с другой раз- делять контекст обсуждения (говорим мы о сиюминутном состоянии ощущения счастья или об интегральном ощущении жизни как результата).

Целью данной статьи является рассмотрение взаимозависимости и взаимовлияния двух факторов счастья (ситуативного и интегрального тона), а также характера динамики их изменения. Данный анализ, по мнению автора, позволит более системно и точно определять и описывать текущее состояние человека и его динамику, как для целей терапии, так и в процессе коучинга и самокоучинга.

\section{Взаимовлияние ситуативного и интегрального тона}

Ощущение счастья конкретного индивидуума в этих двух аспектах совершенно различны, как по характеру переживания, так и по динамике изменения. Прежде всего, они могут не совпадать в конкретный момент времени и могут даже быть прямо противоположны по модальности. Так, например, в жизни человека объективно все может быть во всех отношениях хорошо, и в целом полностью его удовлетворять. То есть человек в целом очень счастлив - его интегральный тон достаточно высокий. Но с ним может случиться какое-то неприятное событие - случайный конфликт, неудачные переговоры, потеря крупной суммы денег, травма и тому подобные относительно случайные негативные события. В этот момент человек испытывает отрицательные эмоции, а возможно и физические страдания, ни о каком переживании счастья в настоящий момент не может быть и речи - его ситуативный тон крайне низок. Подобная ситуация не может быть охарактеризована в целом как счастье или несчастье. Но ее достаточно точно можно охарактеризовать как локальное понижение ситуативного тона при достаточно высоком интегральном тоне.

Возможны и обратные ситуации. Объективно жизнь конкретного человека может характеризоваться как несчастная - материальное неблагополучие, неустроенная личная жизнь, отсутствие достижений и перспектив, постоянно негативное настроение и болезни. История жизни объективно не выглядит позитивной - интегральный тон находится на очень низком уровне. Однако, случаются какие-то пусть небольшие, но приятные события хорошая погода, небольшая сумма свободных денег, неожиданная приятная компания и т.п. Человеку удается забыть про жизненные невзгоды, и он просто наслаждается текущим моментом - ситуативный тон его достаточно высокий. Опять же охарактеризовать ситуацию как счастливую невозможно, но она хорошо описывается как достаточно высокий ситуативный тон, на фоне низкого интегрального тона. Таким образом, можно говорить об относительной независимости интегрального и ситуативного тона. 
Однако, с другой стороны совершенно очевидно, что между этими характеристиками имеется достаточно четкая зависимость. Так, например, у человека с высоким интегральным тоном, очевидно, сформирован набор личных качеств, социальных связей и контактов, а также определенная материальная база, которые позволили ему достигнуть, удовлетворяющего его уровня жизни. Но эта база обеспечивает и более простое воспроизводство позитивных переживаний, по крайней мере, в материальной и социальной сфере. В частности, его личные размышления по поводу собственной жизни, прошлого и будущего, а также представление другим результатов своего жизненного пути, в том или ином контексте, и планов на будущее будут сопровождаться позитивными эмоциональными переживаниями (формировать состояние высокого ситуативного тона).

В то время, как человек с низким интегральным тоном, неудовлетворенный общим положением вещей в своей жизни, будет с высокой вероятностью чаще испытывать негативные переживания (состояния низкого ситуативного тона), в частности рефлексируя свое текущее жизненное положение.

Безусловно, проследить эту корреляцию интегрального и ситуативного тона можно только в контексте конкретной личности, с учетом ее жизненных устремлений и представления о желаемых жизненных достижениях и обстоятельствах. Разные люди могут совершенно поразному оценивать конкретные обстоятельства своей жизни и оценивать значения тех или иных достижений и других характеристик своей жизненной истории. Так, например, можно привести множество примеров [11], людей достаточно успешных и преуспевающих, при этом совершенно не удовлетворенных своей жизнью, страдающих от хронической депрессии (имеющих устойчиво низкий ситуативный тон). Но также имеется множество примеров людей, по общим меркам не особо преуспевающих в общепринятом смысле [15], но при этом жизнерадостных и оптимистичных (имеющих устойчиво высокий ситуативный тон). Все это указывает на то, что интегральный тон нужно оценивать во всей полноте жизненных обстоятельств, и с учетом индивидуальных особенностей каждой конкретной личности.

Однако, можно выделить и общие универсальные корреляты, вносящие вклад в уровень интегрального тона, присущие всем людям. Так, например, хорошее состояние физического и психического здоровья, безусловно, будет иметь непосредственную прямую корреляцию с интегральным тоном и обеспечит более устойчивое воспроизводство позитивных ситуативных состояний. «Состояние счастья в значительной степени зависит от того, как респондент оценивает состояние своего здоровья: чем выше оценивается состояние здоровья, тем чаще респонденты относят себя к категории счастливых людей». [7, с. 22]
С другой стороны, физическая деградация работы дофаминовой и эндорфиновой компонент системы позитивного подкрепления (двух основных источников позитивных эмоциональных состояний) приведет к сложности воспроизводства состояний высокого ситуативно тона, и к безусловному снижению тона интегрального [10].

В общем, делая вывод о соотношении интегрального тона личности (тех или иных качеств и навыков, текущего материального и социального положения) и воспроизводством ситуаций, характеризующихся высоким или низким ситаутивным тоном, можно сказать следующее. Имеется набор объективных универсальных коррелятов интегрального тона присущих всем людям (например, состояние физического здоровья, жизненный оптимизм, стрессоустойчивость и пр.), которые однозначно будут способствовать формированию более позитивного ситуативного фона (увеличивать процент ситуаций высокого ситуативного тона). С другой стороны, можно выделить и другие составляющие интегрального тона (конкретные знания, умения и навыки; характеристики внешнего окружения и материального благополучия), которые будут специфичны для конкретной индивидуальной личности. В частности, определенные характеристики могут повышать интегральный тон у одного человека и никак не влиять, а возможно и понижать на интегральный тон другого. По мнению автора, анализ этих характеристик интегрального тона (объективно-универсальных и субъективно-индивидуальных) может внести существенный вклад в дальнейшее понимание феномена счастья.

\section{$\triangle$ инамика изменения ситуативного и интегрального тона}

Ситуативный и интегральный тон имеют совершенно различную динамику и скорость изменения. Очевидно, что ситуативный тон может меняться практически мгновенно в зависимости не только от внешних обстоятельств, но и от собственных мыслей человека. Например, негативное воспоминание, или предвкушение негативных событий может резко понизить ситуативный тон, а приятное воспоминание наоборот. Несмотря на то, что изменения ситуативного тона часто имеют исключительно субъективную причину, они имеют совершенно конкретную объективную природу. Изменения ситуативного тона объективируются в изменении текущего эмоционального фона, которые отражаются в состояния нервной и эндокринной систем и активизации тех или иных гормональных и нейромедиаторных подсистем. Так, например, предвкушение опасного события может вызвать повышение уровня кортизола, а воспоминание о конфликте - уровня адреналина.

С другой стороны, при достаточной степени натренированности, человек в состоянии управлять изменениями ситуативного тона. С применением тех или иных 
физических упражнений и психотехник предупреждать негативные изменения и формировать оптимальный текущей задаче ситуативный тон. И эти изменения могут происходить практически мгновенно, за считанные секунды. Изучение данных психотехник и формирование навыков в их применении в конкретных жизненных ситуациях, представляется еще одним крайне перспективным направлением развития научных исследований.

В отличие от изменения ситуативного тона, интегральный тон меняется крайне медленно, ведь он связан с формированием личностных характеристик и навыков, а также структуры материального и социального окружения. Очевидно, что это процессы достаточно инертны. Конечно, возможны различные катастрофы и случайные успехи, которые могут вносить резкие изменения в обстоятельства жизни. Но даже такие радикальные изменения не затрагивают всего комплекса обстоятельств жизни человека и не меняют его интегральный тон моментально, хотя и могут послужить причиной постепенного его изменения. Но подобные, даже самые радикальные изменения все-таки, как правило, не приводят к столь же существенному изменению интегрального тона. Как показывают, например, исследования изменений происшедших в жизни людей, выигравших крупные суммы в лотерею [14], такие изменения в уровне материального благополучия могут приводить к усилению ощущения одиночества. И резко изменив стиль жизни сразу после получения выигрыша, получившие его, в большинстве случаев, постепенно возвращаются к своему привычному образу жизни, как правило, утратив случайно обретенные богатства. Известны и обратные примеры [8], когда люди с высоким интегральным тоном, демонстрировали высокую продуктивность даже с существенными физическими повреждениями, которые, казалось бы, не совместимы с активным творческим образом жизни.

\section{Зависимость Аиапазона изменения ситуативного тона от уровня интегрального тона}

Помимо отмеченной нами ранее прямой зависимости частоты воспроизводства ситуаций высокого или низкого ситуативного тона от общего уровня интегрального тона личности, так же можно сделать предположение и о зависимости диапазона изменения ситуативного тона от уровня интегрального тона человека. Так, например, человек, имеющий крайне низкий интегральный тон, не имеющий необходимых личностных ресурсов и соответствующего материального и социального окружения, будет преимущественно испытывать низкотональные состояния. Это касается как возможности удовлетворения базовых физиологических потребностей, потребностей в общении, так преимущественно негативных эмоциональных переживаний, порождённых негативными обстоятельствами жизни. И диапазон изменений ситуативного тона будет достаточно низкий, в районе мини- мальных значений. Конечно, это не касается тех случаев, когда человек осознанно выбирает аскетический способ существования, порожденный стремлением к духовному совершенству или какими-то иными стимулами, и обладает всеми необходимыми личными ресурсами и навыками.

В то же время, диапазон колебаний ситуативного тона человека с предельно высоким уровнем интегрального тона, обладающего всеми необходимыми для нормального существования и развития навыками, личностными, материальными и социальными ресурсами, так же будет относительно небольшим. Он преимущественно будет находиться в ровном позитивном настроении, адекватно реагируя на изменения внешних обстоятельств, оптимально дозируя конструктивный стресс (эустресс). Как в предельно низком, так и в предельно высоком интегральном тоне диапазон колебаний ситуативного тона будет минимальным, хоть и на разных границах спектра эмоционального тона. В то время как человек со средним интегральным тоном, которому «ни что человеческое не чуждо» с высокой вероятностью будет испытывать самые разнообразные эмоциональные состояния как позитивные (в моменты откровения, творчества, влюбленности), так и негативные (в моменты обиды, гнева, страха и пр.). У человека со средним интегральным тоном, с одной стороны, уже достаточно ресурсов чтобы не испытывать беспробудного горя и физического страдания, то есть не испытывать непрерывно воспроизводящегося состояния крайне низкого ситуативного тона, но с другой, ему еще недостаточно ресурсов, личностных характеристик и навыков, чтобы преодолевать все жизненные трудности и негативные обстоятельства, с которыми любому живущему человеку приходится постоянно сталкиваться.

\section{Итоги}

В данной работе мы сделали попытку развить идеи двухфакторной модели счастья Даниэла Канемана, которая базируется на традиционном двухфакторном подходе к рассмотрению счастья получившему начало еще в древнегреческой философии. Предложили варианты адекватного перевода терминов experienced well-being, remembering of well-being используемых Канемана для обозначения двух этих факторов, а также провели анализ степени взаимозависимости этих факторов, динамики и диапазона их изменения.

Очевидно, что в данной работе мы только наметили общий контур рассуждений и дальнейших исследований в области, как более четкого определения феномена ситуативного и интегрального тона, их характеристик, способов оценки их уровня и главное методов их повышения, как инструментов повышения счастья индивидуума, как в терапии, так и в коучинге, а также в самокоучинге. 


\section{ЛИТЕРАТУРА}

1. Аврелий М. Размышления. Л.: Наука, 1985. 246 стр.

2. Аристотель. Никомахова этика. «ЭКСМО-Пресс», Москва, 1997. 496 стр.

3. Королева, М. Н. Счастье как социокультурный феномен. Диссертация на соискание ученой степени кандидата социологических наук. Москва 2013. 166 стр.

4. Левит Л.3. Индивидуальный потенциал и его реализация. Минск: РИВШ, 2014.661 стр.

5. Пискарёв Павел Михайлович. «Метамодерн и интегративная методология гуманитарного знания». диссертация на соискание ученой степени доктора психологических наук (2019). 461 стр.

6. Рыжов Б.Н., Смоловская Л.Б.. Методика самооценки эмоционального тона и активности СЭТА. Системная психология и социология, 2018, № 3 (27).

7. Черныш М.Ф. Факторы, влияющие на переживание счастья в российском обществе. Социологическая наука и социальная практика. № 2(26), 2019.

8. 25 вдохновляющих примеров людей, которые добились успеха, несмотря ни на что. - [Электронный документ]. - Режим доступа: https://coolday. today/25-vdohnovlyayush-ih-primerov-lyudej-kotorye-dobilis-uspeha-nesmotrya-ni-na-chto.html

9. Davis W. A theory of happiness / W. Davis // American Philosophical Quarterly. 1981. Vol. 14. № 1. P. 111-120

10. Esch T, Stefano GB. The neurobiology of pleasure, reward processes, addiction and their health implications. Neuro Endocrinol Lett. 2004 Aug;25(4):235-51.

11. Gartner, John D. The Hypomanic Edge: The Link Between (A Little) Craziness and (A Lot of) Success in America. Simon \& Schuster (June 18, 2011 ), 368 pages.

12. Kahneman, D., Diener, E., \& Schwarz, N. (Eds.). (1999). Well-being: The Foundations of Hedonic Psychology. New York: Russell Sage Foundation.

13. Kahneman D. Objective happiness. 1999 / D. Kahneman, E. Diener, N. Schwarz // Well-being: The foun-dations of hedonic psychology. Russell Sage Foundation Publications, 2003. 605 pages.

14. Kathleen D. Vohs, Nicole L. Mead, Miranda R. Goode. The Psychological Consequences of Money. Science 314, 1154 (2006);

15. Sonja Lyubomirsky. The How of Happiness: A New Approach to Getting the Life You Want. Penguin Books (December 27, 2007), 380 pages.

16. Sumner L.W. Welfare, happiness, and ethics/ L.W. Sumner. Oxford University Press, USA, 1999, 256 pages. 